\title{
Tai-Chi-Chuan Exercise Improves Pulmonary Function and Decreases Exhaled Nitric Oxide Level in Both Asthmatic and Nonasthmatic Children and Improves Quality of Life in Children with Asthma
}

\author{
Hsin-Chia Lin, ${ }^{1}$ Hao-Pai Lin, ${ }^{1}$ Hsin-Hui Yu, ${ }^{1}$ Li-Chieh Wang, ${ }^{1}$ Jyh-Hong Lee, ${ }^{1}$ \\ Yu-Tsan Lin, ${ }^{1}$ Yao-Hsu Yang, ${ }^{1}$ Pei-Yi Li, ${ }^{2}$ Wei-Zen Sun, ${ }^{3}$ and Bor-Luen Chiang ${ }^{4}$ \\ ${ }^{1}$ Department of Pediatrics, National Taiwan University Hospital, Taipei, Taiwan \\ ${ }^{2}$ Taiwan Tai Chi \& Wushu Academy, Taipei, Taiwan \\ ${ }^{3}$ Department of Anesthesiology, National Taiwan University Hospital, Taipei, Taiwan \\ ${ }^{4}$ Department of Medical Research, National Taiwan University Hospital, Taipei, Taiwan
}

Correspondence should be addressed to Wei-Zen Sun; wzsun@ntu.edu.tw and Bor-Luen Chiang; gicmbor@ntu.edu.tw

Received 25 March 2016; Revised 19 June 2016; Accepted 21 March 2017; Published 13 April 2017

Academic Editor: Yi Yang

Copyright (c) 2017 Hsin-Chia Lin et al. This is an open access article distributed under the Creative Commons Attribution License, which permits unrestricted use, distribution, and reproduction in any medium, provided the original work is properly cited.

\begin{abstract}
Tai-Chi-Chuan (TCC) is an exercise of low-to-moderate intensity which is suitable for asthmatic patients. The aim of our study is to investigate improvements of the lung function, airway inflammation, and quality of life of asthmatic children after TCC. Participants included sixty-one elementary school students and they were divided into asthmatic $(n=29)$ and nonasthmatic $(n=$ 32) groups by the International Study of Asthma and Allergies in Childhood (ISAAC) questionnaire. Among them, 20 asthmatic and 18 nonasthmatic children volunteered to participate in a 60-minute TCC exercise weekly for 12 weeks. Baseline and postintervention assessments included forced expiratory volume in one second (FEV1), forced vital capacity (FVC), peak expiratory flow rate (PEFR), fractional exhaled nitric oxide (FeNO) level, and Standardised Pediatric Asthma Quality of Life Questionnaire (PAQLQ(S)). After intervention, the level of FeNO decreased significantly; PEFR and the FEV1/FVC also improved significantly in both asthmatic group and nonasthmatic group after TCC. The asthmatic children also had improved quality of life after TCC. The results indicated that TCC could improve the pulmonary function and decrease airway inflammation in both children with mild asthma and those without asthma. It also improves quality of life in mild asthmatic children. Nevertheless, further studies are required to determine the effect of TCC on children with moderate-to-severe asthma.
\end{abstract}

\section{Introduction}

Asthma is the most common chronic disease among children in the world [1]. It is characterized by chronic inflammation of the airways, airway hyperresponsiveness, and remodeling. Due to recurring cough, wheezing, breathlessness, and chest tightness, asthma impacts the quality of life of individuals greatly, even under current medical treatment and environmental control in adults or in children. The prevalence of asthma among school age children was estimated to be $7.4 \%$ in central Taiwan in 2009 [2].

Although exercise is beneficial with regard to asthma control, exercise is a common trigger for the asthma symptom of bronchospasm. For this reason, asthmatic children may avoid vigorous activity due to concerns regarding the worsening of asthma symptoms or deconditioning due to inactivity. This might result in further reduced physical fitness and social well-being [3]. Exercise that has a minimal impact regarding exercise-induced bronchospasm such as swimming is better tolerated among asthmatic children [3, 4]. Approximately 20 to 30 minutes of exercise at $60 \%$ to $85 \%$ of maximum heart rate four or five times a week is recommended for asthmatic patients [5]. A recent review demonstrated that physical training showed significant improvements in maximum oxygen uptake, though no effects were observed in other measures of pulmonary function [6]. Recent studies 
have shown that yoga exercise three times a week for 10 weeks could improve quality of life and decrease asthmatic symptoms in women with mild-to-moderately persistent asthma [7].

Tai-Chi-Chuan (TCC) exercise is often referred to as "meditation through movement," incorporating elements of balance, postural alignment, and concentration [8]. It is an exercise that combines deep diaphragmatic breathing and relaxation with many fundamental postures, which is suitable for asthmatic patients. An increased oxygen uptake up to $50 \%$ of the peak oxygen consumption and heart rate within $58 \%$ of the heart rate range were noted during the TCC sessions, suggesting that TCC is a moderate-intensity exercise that is aerobic in nature $[9,10]$. Compared to other exercises of an equal intensity, TCC was shown to have a significantly lower ventilatory equivalent $\left(\mathrm{V}_{\mathrm{E}} / \mathrm{V}_{\mathrm{O} 2 \mathrm{MAX}}\right)$ [11]. TCC exercise is beneficial to cardiopulmonary function, mental control, flexibility, and balance control [12]. Studies also showed that TCC had an anti-inflammatory effect, including reducing monocytes counts, enhancing CD4+/CD8+ $\mathrm{T}$ cells ratio, and increasing regulatory $\mathrm{T}$ cells [13]. Enhanced immune function after TCC exercise has also been observed, including increases in the levels of IgG, increasing the numbers and activity of natural killer cells [12]. Our previous smallscale study showed that pulmonary function significantly improved in asthmatic children after 3 months of TCC, but the improvement in symptoms was not significantly different between the TCC group ( 15 children) and control group (15 children) [14]. The aim of this study is to investigate the differences regarding the lung function, airway inflammation, and quality of life of asthmatic children after TCC exercise.

\section{Materials and Methods}

2.1. Study Subjects and TCC Exercise. We recruited 61 students (29 asthmatic children and 32 nonasthmatic children) from an elementary school in Taipei City. Subjects with congenital heart disease, chronic cardiopulmonary disease, rheumatic or autoimmune disease, neuromuscular disease, and other systemic diseases were excluded. Asthma was initially screened through the International Study of Asthma and Allergies in Childhood (ISAAC) written questionnaire translated in Chinese [15]. The diagnosis of asthma was further confirmed by pediatric allergist/immunologists. All the asthmatic participants had mild asthma without taking any controller medication. Informed consent was obtained from each participant. This study has been approved by the Institutional Review Board of National Taiwan University Hospital.

Among the recruited students, 20 asthmatic and 18 nonasthmatic children volunteered to participate in a 60minute TCC exercise class once a week for 12 consecutive weeks. Subjects in the TCC training group learned to perform Chen-style TCC standardised movements under the guidance of two TCC teachers (P.-Y. Li and C.-H. Sun) at school. Children were asked to practice TCC exercise assisted by videos daily (Figure 1). Non-TCC training participants were instructed not to begin any new activities but to maintain their daily activities.
Given the limited time frame, the TCC course was specifically designed as a therapy for asthmatic children, under the following points: being able to draw and hold the attention of children; to improve body flexibility and coordination; to increase muscle power (strength and stamina) of the lower extremities; to improve cardiovascular function through mostly moderate-intensity exercise, with about ten minutes of higher-intensity activity; and to develop attentiveness to posture and breath (breathing methods). Each session followed a sequence of warming-up in circular movements, stretching exercises, TCC walking drills, and TCC "opening and closing" movements in stationary positions.

2.2. Measurements. All of the study subjects were evaluated at the entry and at the end of the study for lung function, fractional exhaled nitric oxide (FeNO), and quality of life, as assessed by the Pediatric Asthma Quality of Life Questionnaire (PAQLQ). The PAQLQ was completed by 18 asthmatic TCC and 5 asthmatic non-TCC subjects.

2.2.1. Lung Function Test. Forced expiratory volume in one second (FEV1), forced vital capacity (FVC), and FEV1/FVC ratio were measured using Micro Medical Super Spiro spirometer in resting status. Peak expiratory flow rate (PEFR) was assayed using a peak flow meter. Data of FEV1, FVC, and PEFR are expressed as the percentage of the predicted value specific for Taiwanese children. None of the participants had taken any short-acting bronchodilator within 4 hours of undergoing spirometry.

2.2.2. Fractional Exhaled Nitric Oxide (FeNO). Fractional exhaled nitric oxide (FeNO) concentrations in exhaled breath are a widely used noninvasive marker of airway inflammation in asthma [16]. FeNO was measured using a NIOX MINO machine before and after the 12-week TCC training. It was measured before spirometric maneuvers, at an exhaled rate of $50 \mathrm{ml} / \mathrm{second}$ maintained within $10 \%$ for more than 6 seconds, and with an oral pressure of 5 to $20 \mathrm{~cm} \mathrm{H}_{2} \mathrm{O}$ to ensure velum closure. Results are expressed as the NO concentration in ppb (equivalent to nanoliters/liter) based on the mean of two or three values within $10 \%$ [17]. Subjects were informed to have a low nitrogen diet prior to the exam to minimize confounders [18].

\subsubsection{Standardised Pediatric Asthma Quality of Life Ques-} tionnaire $(P A Q L Q(S))$. We used the traditional Chinese version of PAQLQ(S) developed in Taiwan, which included 23 questions in 3 domains (symptoms, activity limitation, and emotional function) [19]. The activity domain contains 3 "patient-specific" questions. Children were asked to think about how they have been during the previous week and to respond to each of the 23 questions on a 7-point scale $(7=$ not bothered at all; $1=$ extremely bothered). The overall PAQLQ score was the mean of all 23 responses and the individual domain scores were the means of the items in those domains [20]. The measurement sensitivity and validity of the PAQLQ have been validated in several studies for different countries. A change in score greater than 0.5 on the 7-point scale can be considered clinically important [21-24]. 


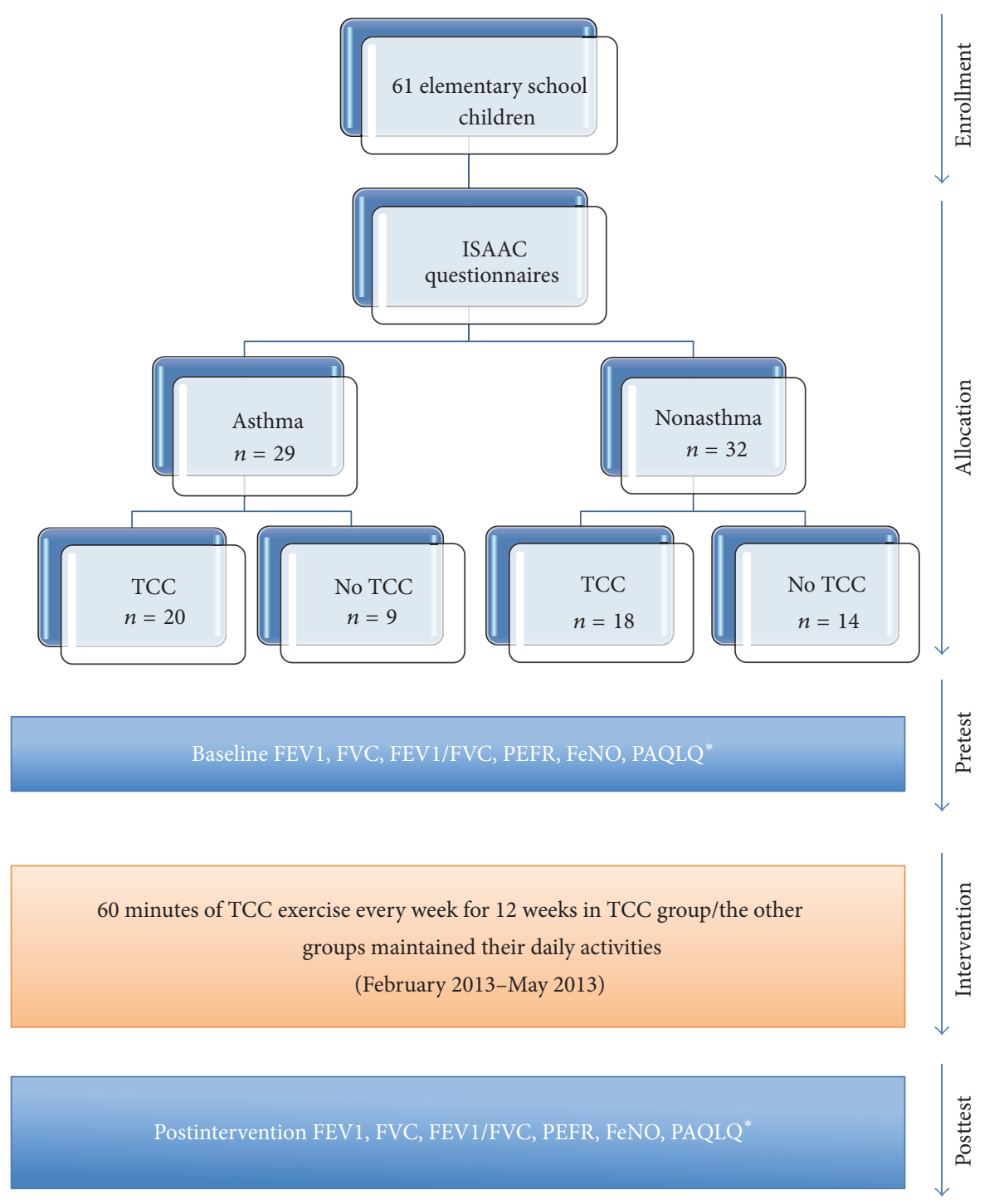

FIGURE 1: *Among asthma group, only 18 in TCC group and 5 in the no TCC group completed the PAQLQ questionnaire.

2.3. Statistical Analysis. Data were compared between groups using the Kruskal-Wallis test or the Mann-Whitney $U$ test for continuous variables. The paired $t$-test or Wilcoxon matchedpairs signed-rank test was used to compare the parameters of continuous variables before and after TCC. Stepwise multiple linear regression models were used to identify the effects of the variables of asthma, TCC, gender, age, weight, height, and baseline values, on outcome changes in lung function (FEV1, FVC, FEV1/FVC, or PEF) and airway inflammation (FeNO). All of these analyses were conducted using SPSS statistical software, version 20 (IBM), and GraphPad Prism software, version 6. A significance level of 0.05 was used for statistical comparisons.

\section{Results}

The demographic and baseline values of outcome variables at the study entry of subjects are given in Table 1. There were no significant differences in age, gender, anthropometric measurement, and pulmonary function between groups at the study entry, except for the baseline FeNO levels (Table 1 and Figures 4 and 3(a)). We observed a higher level of baseline FeNO in the asthmatic non-TCC group, compared with the nonasthmatic non-TCC group $(39.2 \pm 14.9$ versus $26.6 \pm 17.4, p=0.034$ ) (Figure $3(\mathrm{a})$ ). The levels of FEV1/FVC and PEFR increased, while the level of FeNO decreased significantly after TCC exercise for 3 months in both asthmatic and nonasthmatic TCC groups but not in either of the asthmatic or nonasthmatic non-TCC groups (Figures 2(c), 2(d), and 3(c)). There were significantly higher FEV1/FVC levels after 3 months in the asthmatic TCC group compared with the asthmatic non-TCC group (Figure 5). Levels of FEV1 significantly increased only in the asthmatic TCC group after TCC exercise $(p=0.03)$ (Figure 2(a)). There was no significant improvement in FVC after 3 months of TCC exercise for either group (Figure 2(b) and Table 3).

The PAQLQ scores (total scores and score in each domain) showed significant improvement over the 12-week 
FEV1 (\% of predicted)
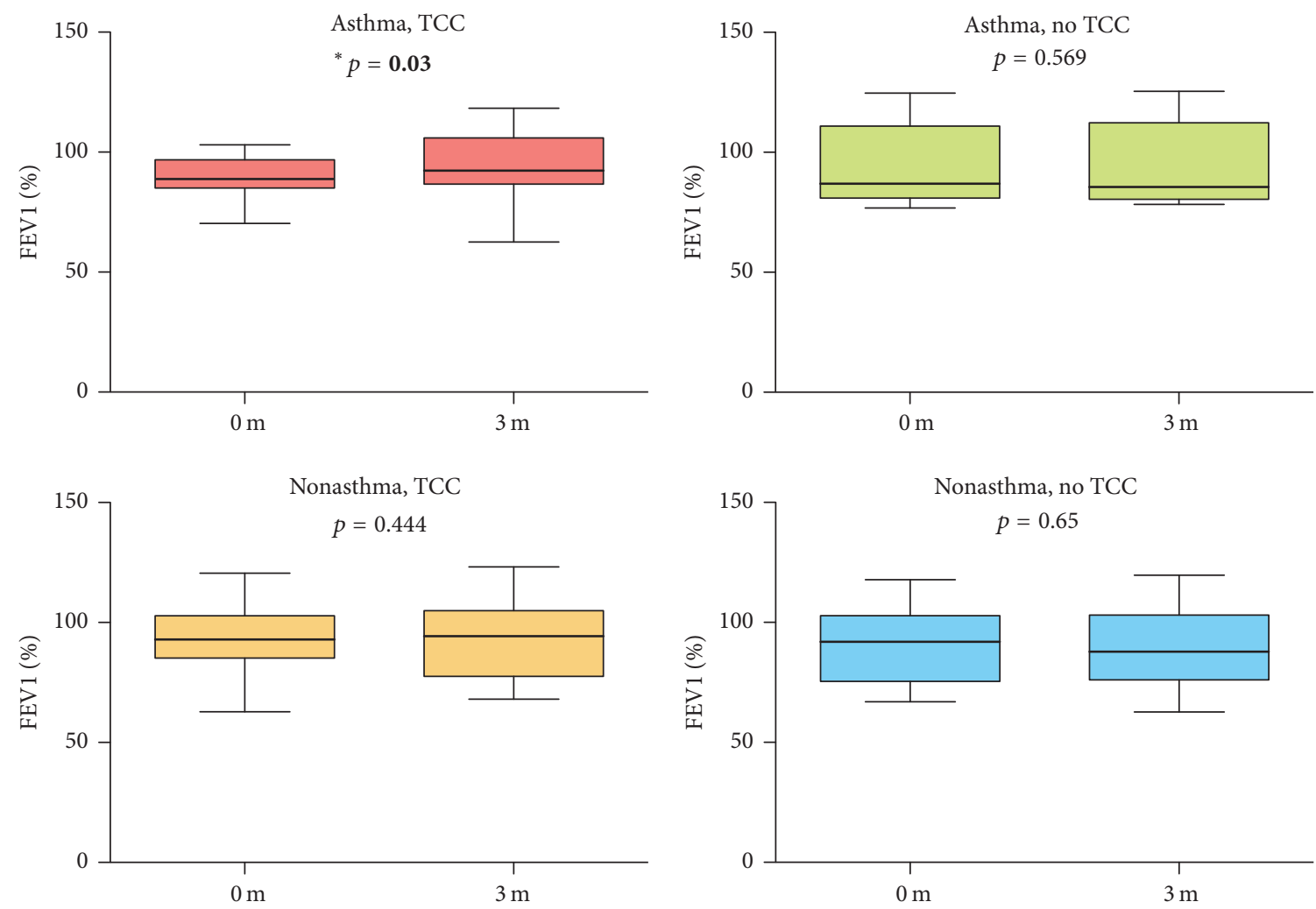

(a)
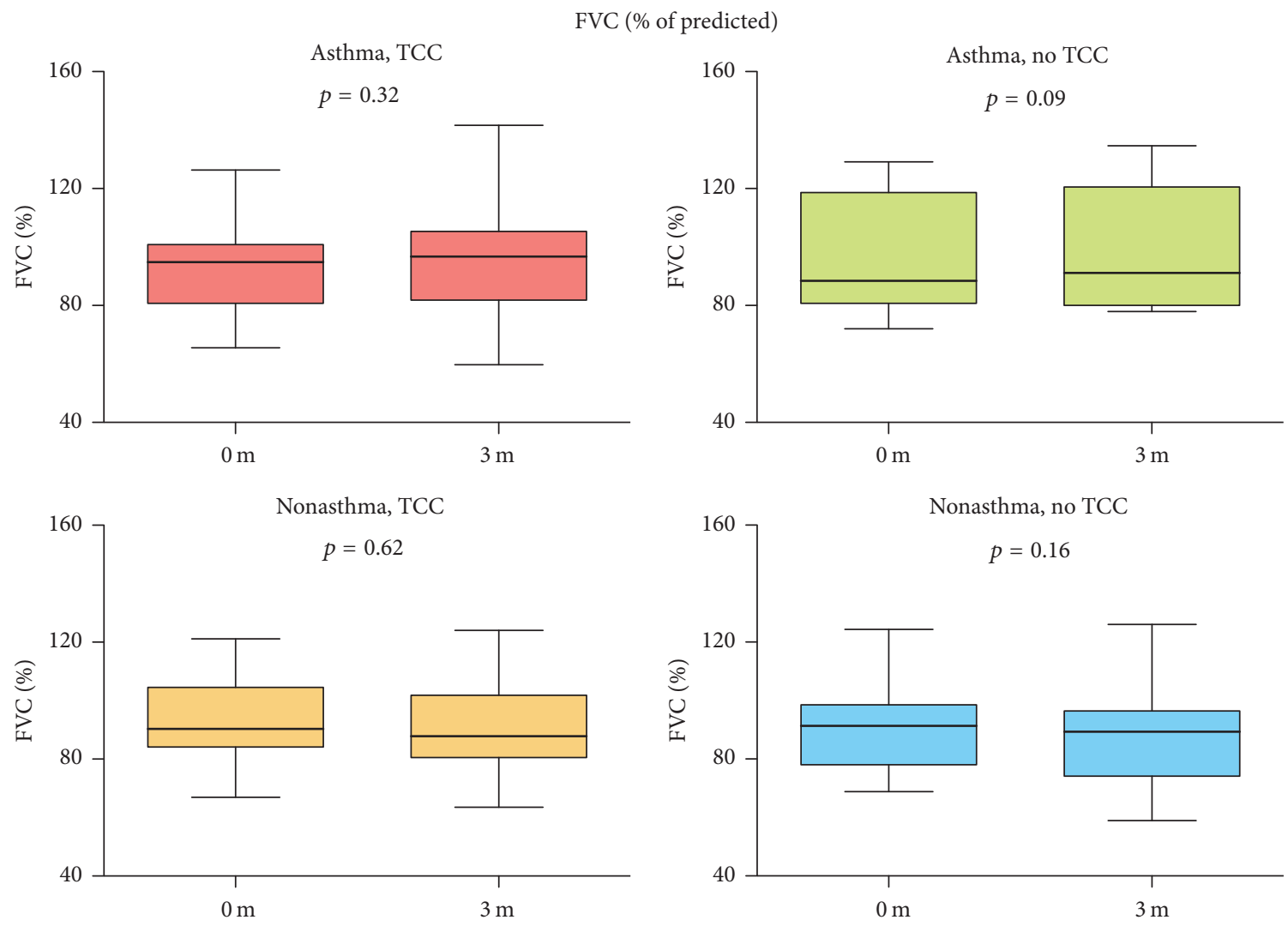

(b)

Figure 2: Continued. 

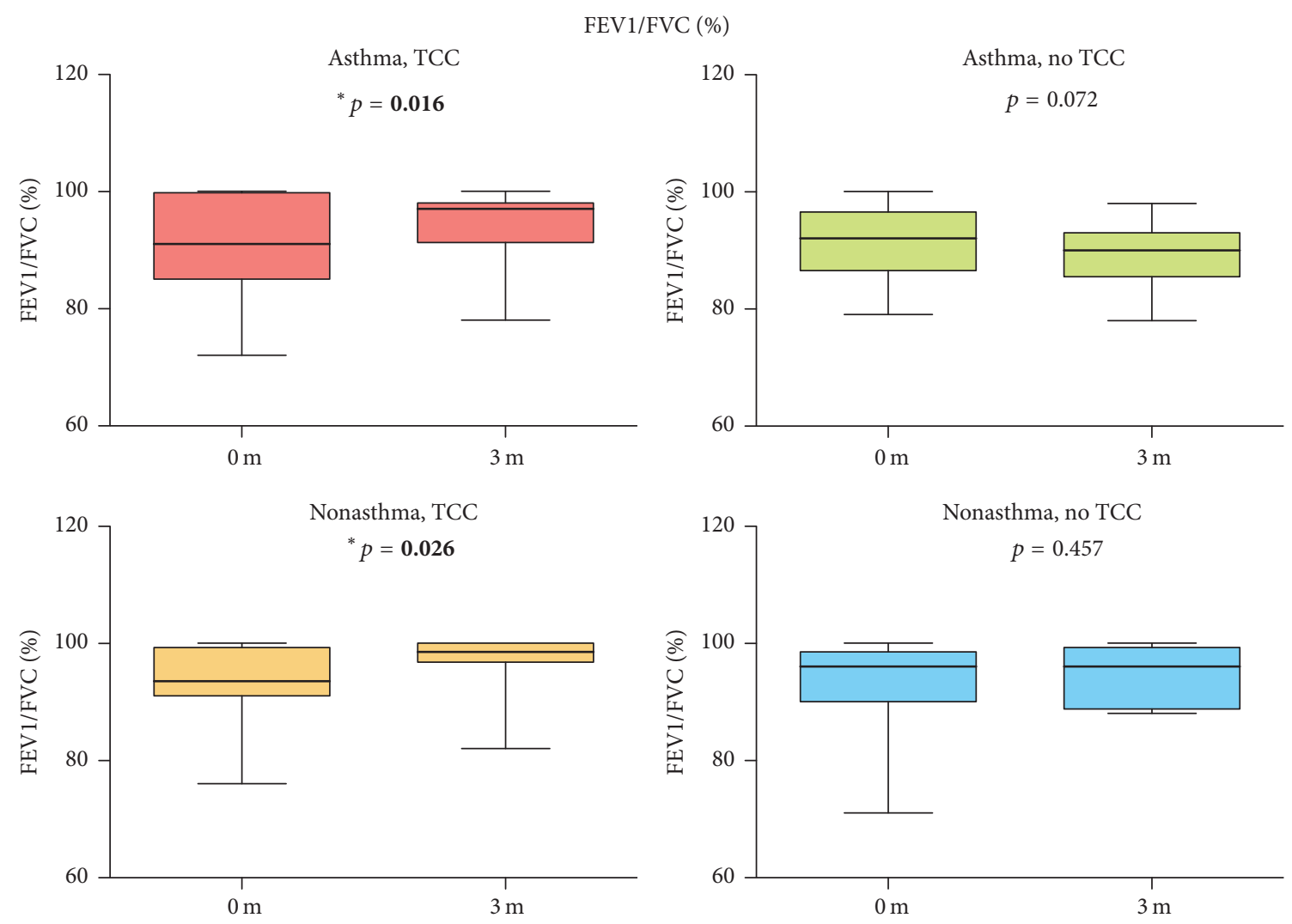

(c)
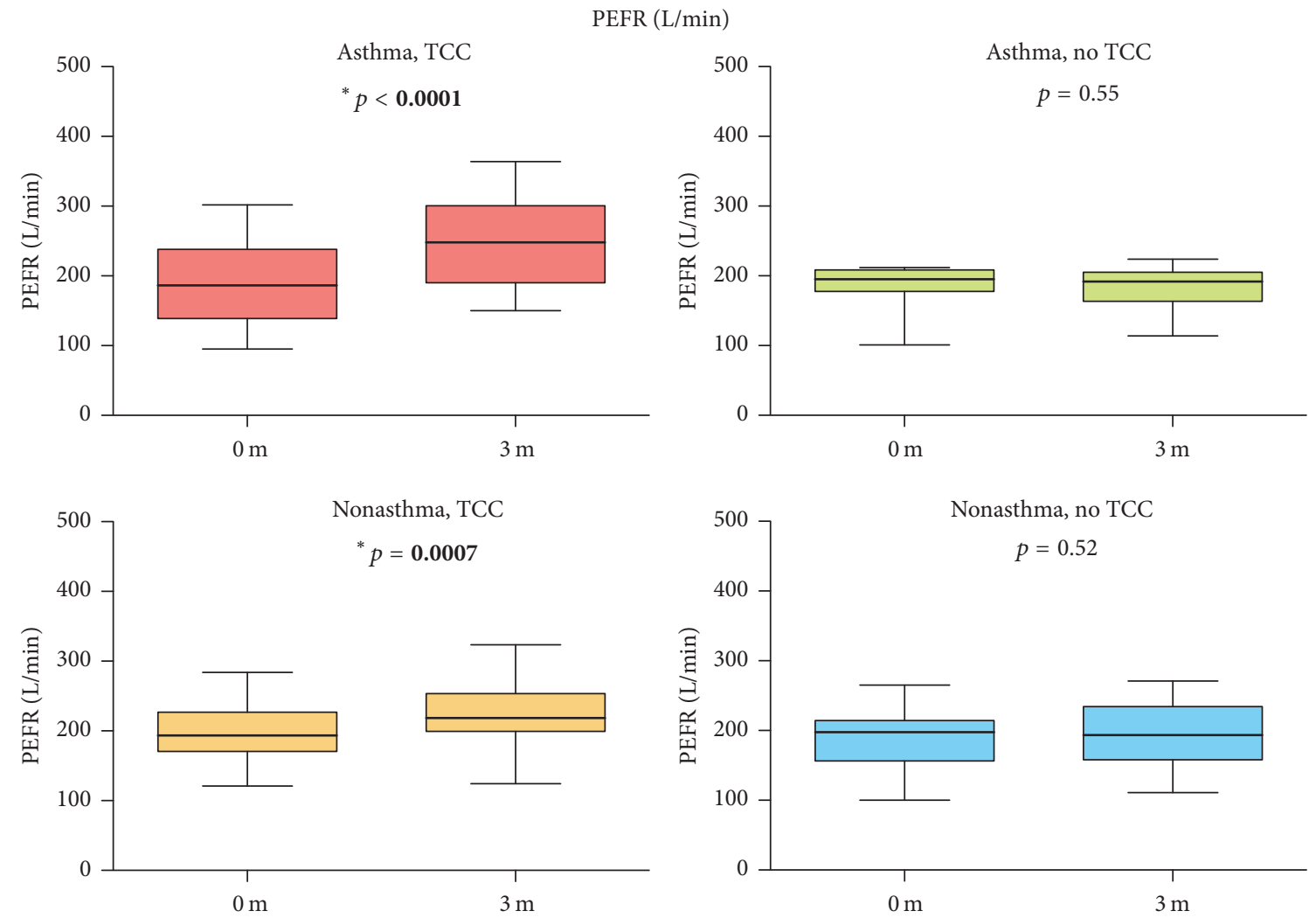

(d)

FIGURE 2: Comparison between pulmonary function at baseline and that after 3 months in each group. Horizontal thick bars indicate median values and box indicates the interquartile range (IQR); upper and lower horizontal bars indicate maximum and minimum values. 


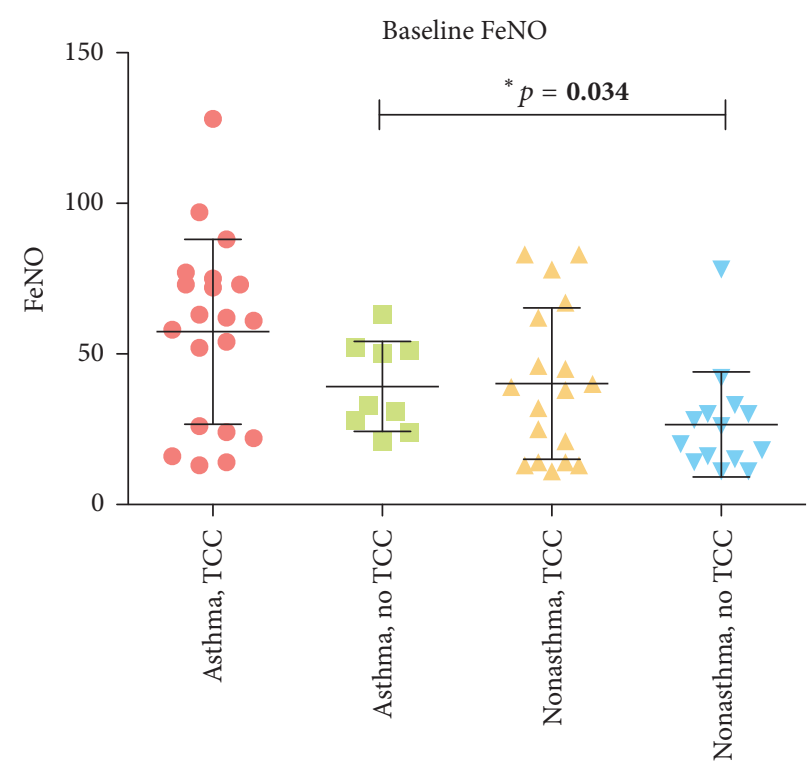

(a)
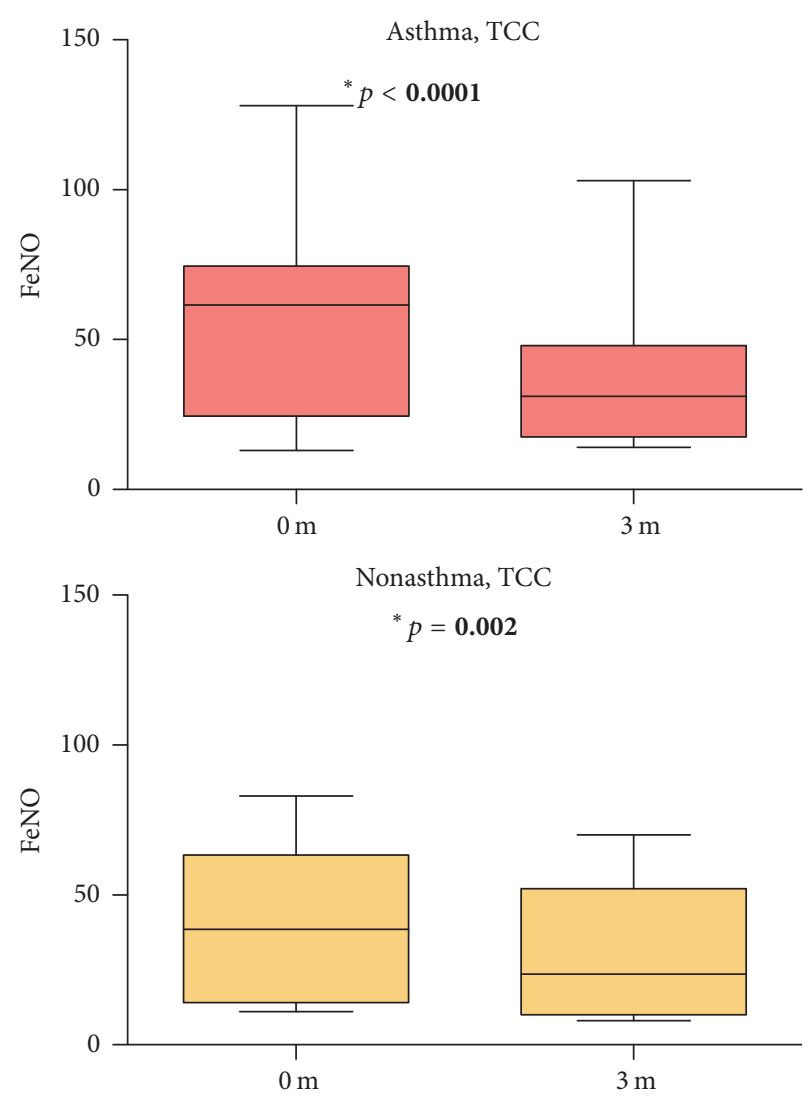

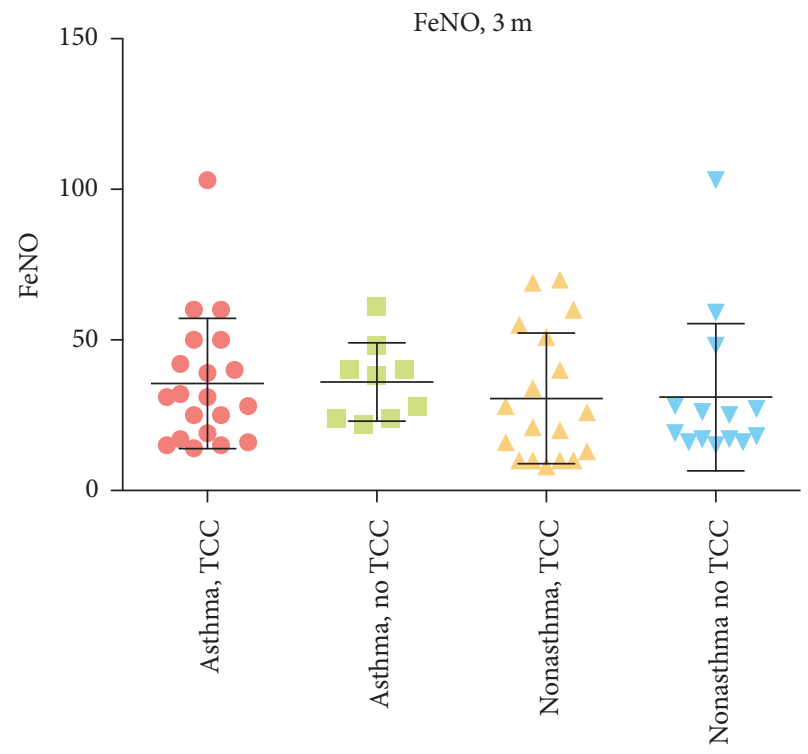

(b)

FeNO
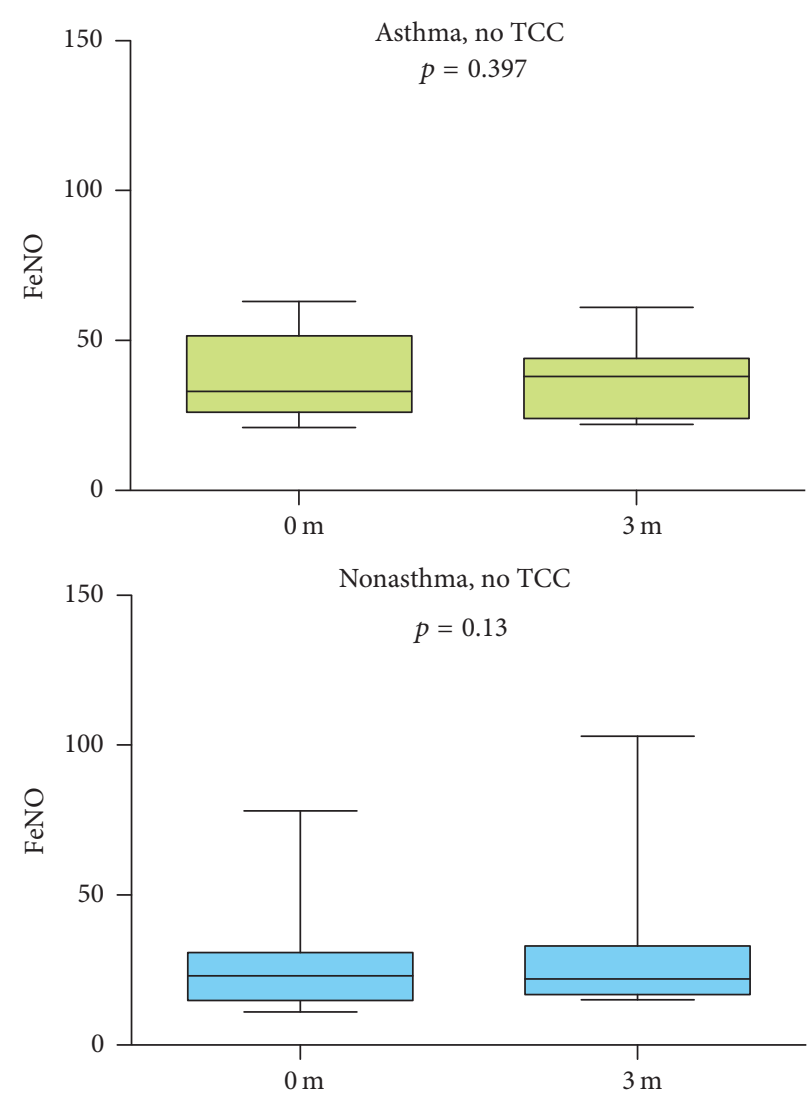

(c)

Figure 3: (a) Baseline FeNO level between 4 groups; (b) FeNO level 3 months later between 4 groups; (c) FeNO level before and after 3 months. 


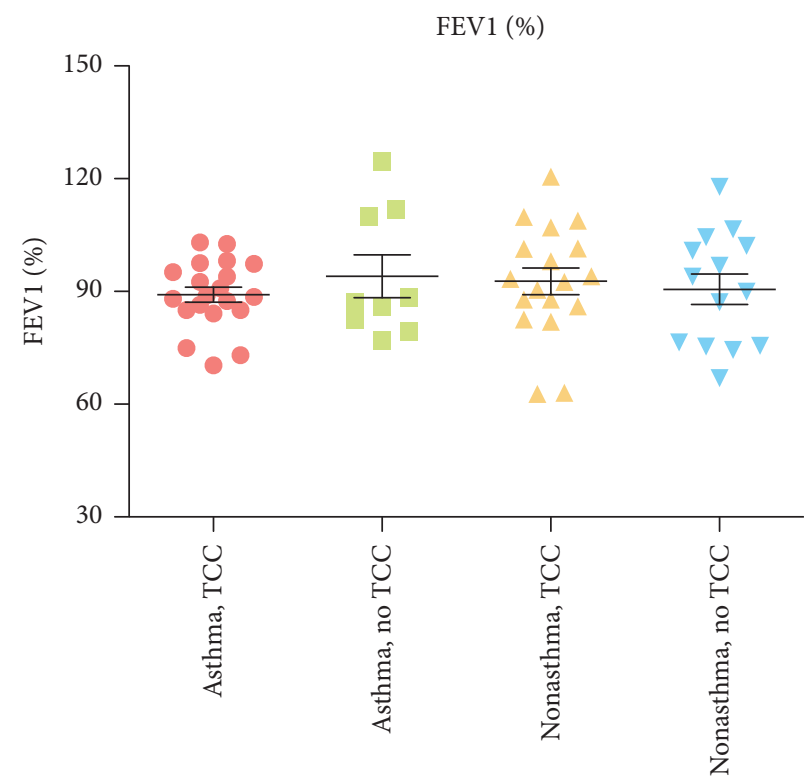

(a)

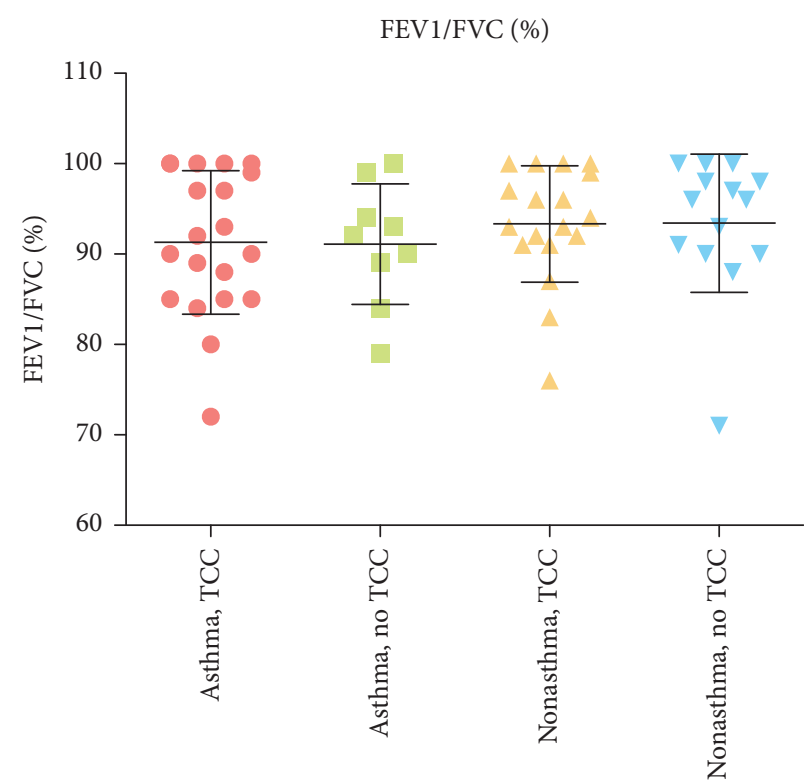

(c)

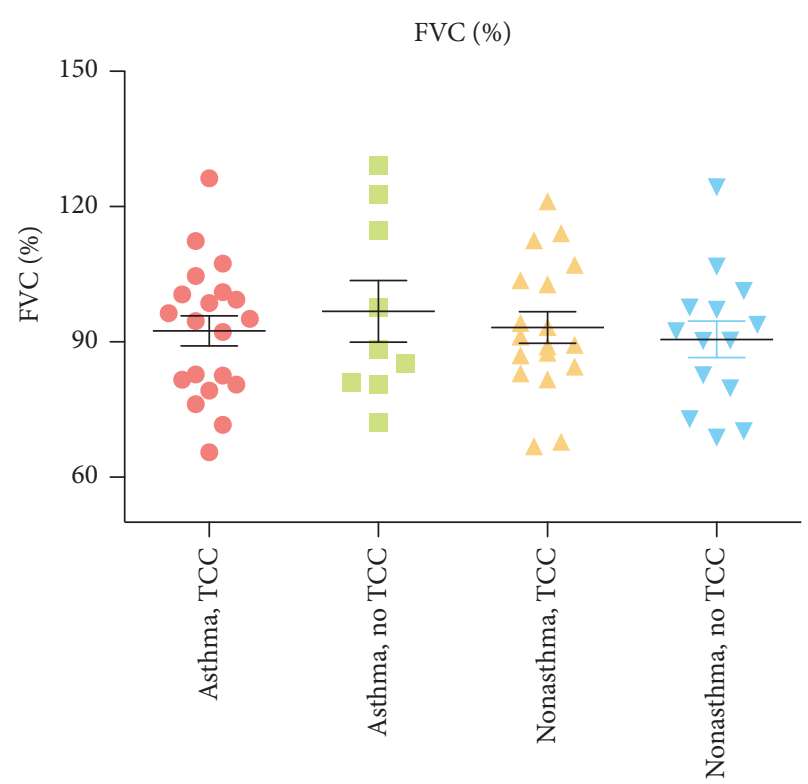

(b)

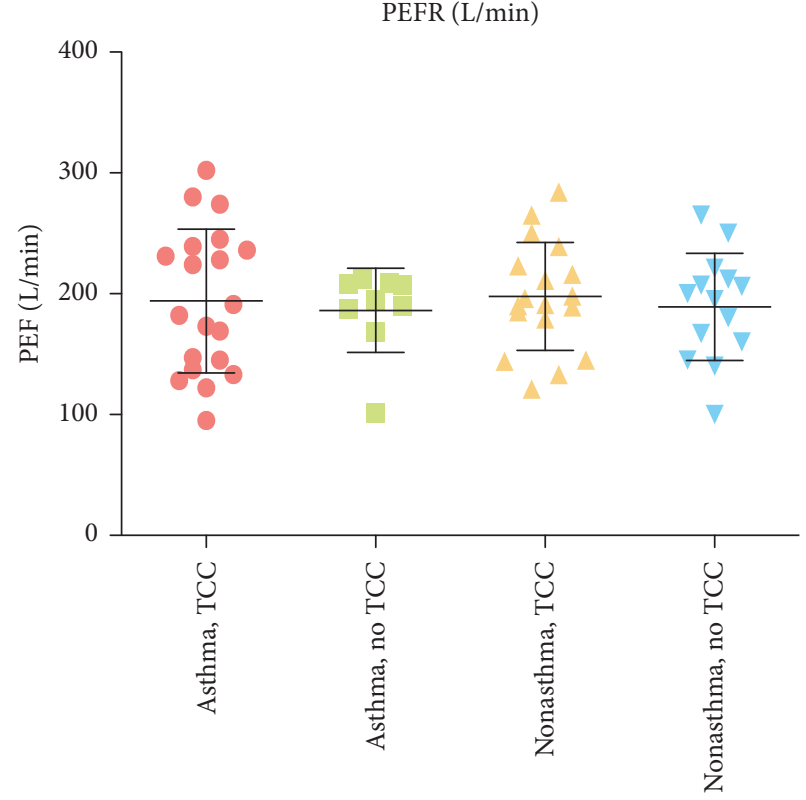

(d)

FIGURE 4: Comparison of baseline pulmonary function between 4 groups.

study period only in the asthmatic TCC group $(p=0.0004)$ (Table 2 and Figure 6). Multiple linear regression models revealed that participation in TCC significantly contributed to improvements in pulmonary function (FEV1, FEV1/FVC, and PEF) and FeNO after adjusting for age, gender, body height, body weight, and baseline values of pulmonary function or FeNO (Table 4). During the study period, none of the asthmatic children had an acute asthma attack or received medication changes for asthma.

\section{Discussion}

This prospective study has demonstrated that participation in 12 weeks of TCC exercise resulted in a significant improvement of pulmonary function and FeNO (indicator of airway inflammation) in asthmatic children, mostly with mild intermittent severity. Such improvement in lung function was also observed in nonasthmatic children. However, quality of life for asthmatic children also significantly improved after TCC exercise, as assessed by the PAQLQ scores in each 


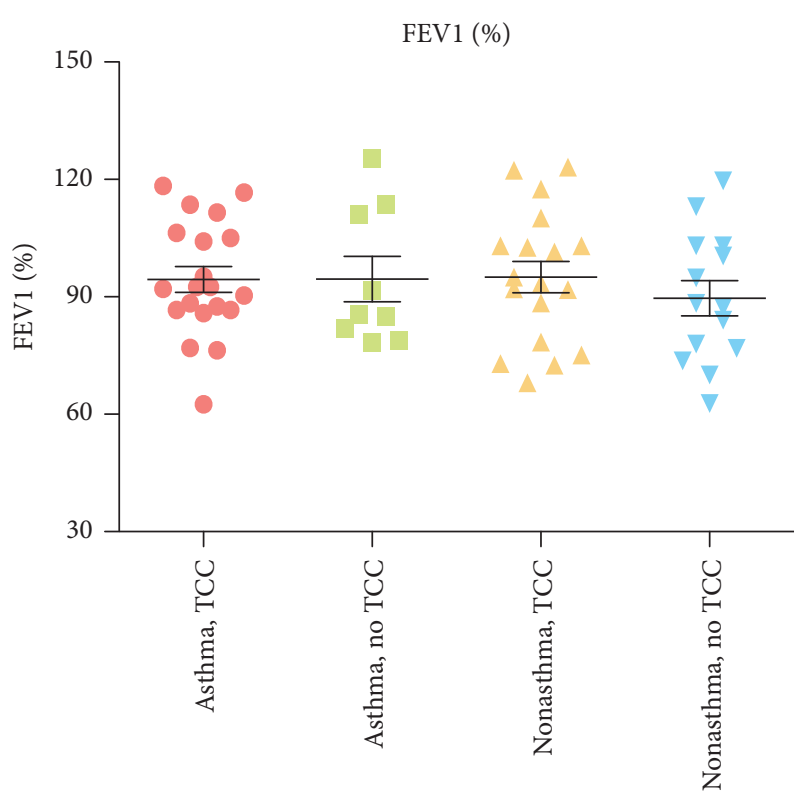

(a)

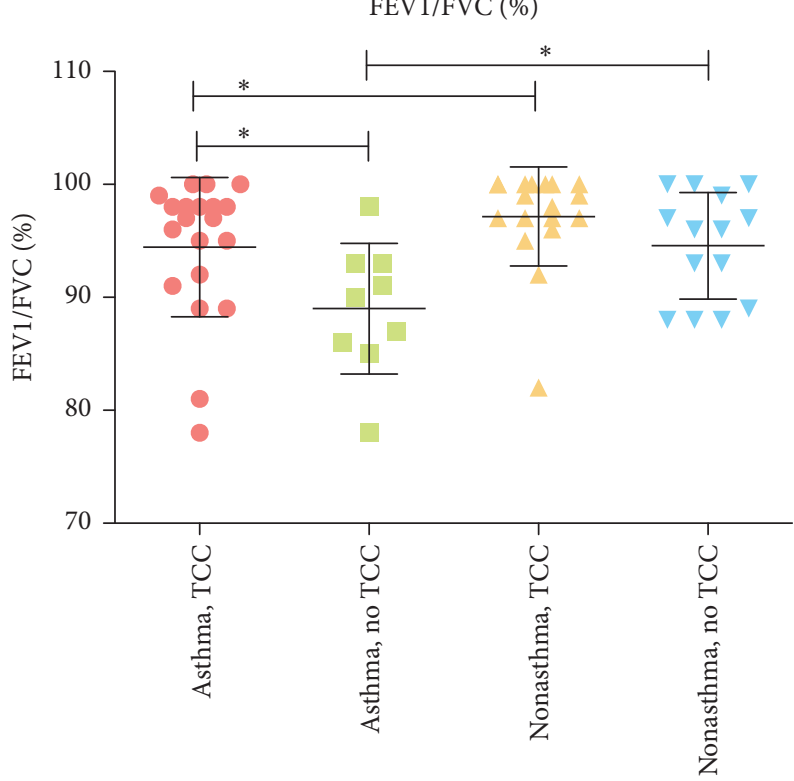

(c)

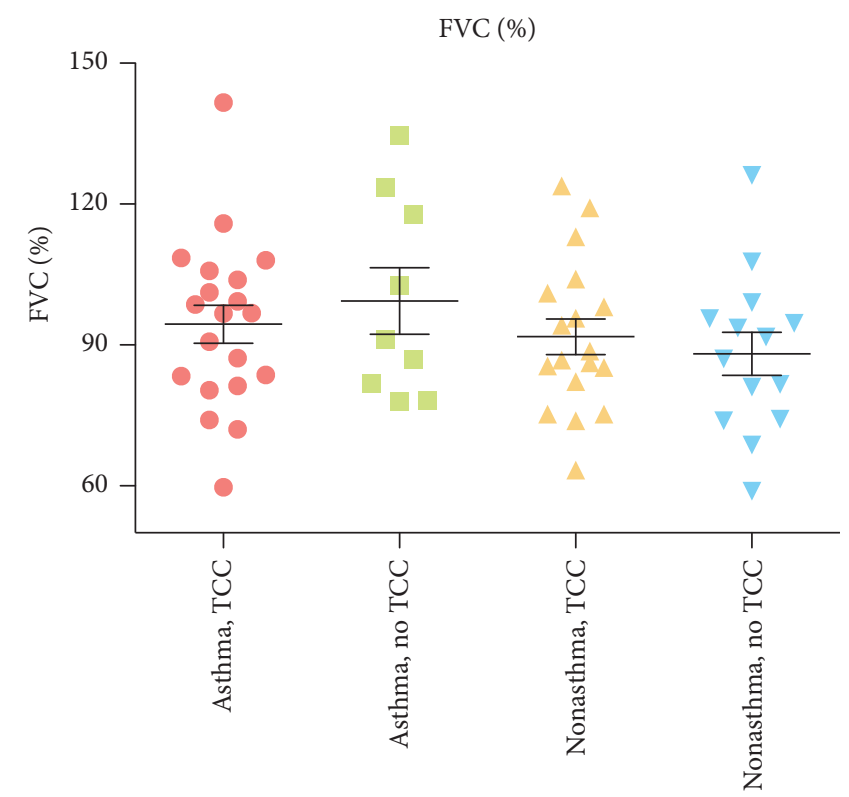

(b)

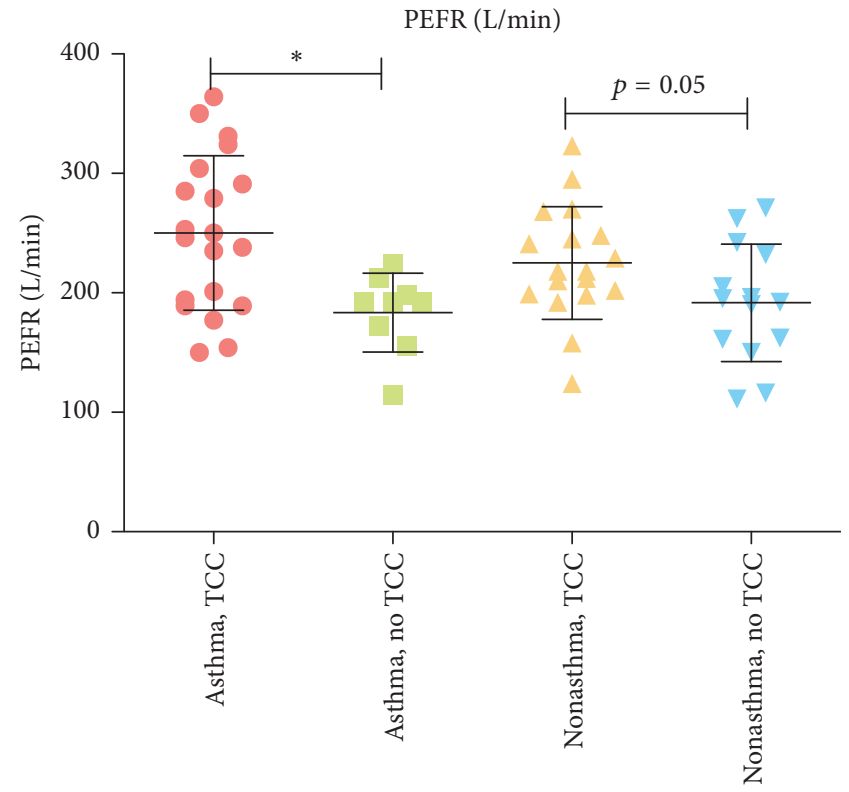

(d)

FIGURE 5: Comparison of pulmonary function between 4 groups after 3 months. $*$ indicates significant difference $(p<0.05)$.

domain, namely, asthmatic symptoms, activity limitation, and emotional function. Our previous study showed a similar result of improvement in pulmonary function after TCC for asthmatic children [14]. The favorable effects of TCC on pulmonary function and quality of life observed in this study are consistent with the findings in a recent metaanalysis demonstrating that exercise training may improve asthma symptoms, quality of life, exercise capacity, bronchial hyperresponsiveness, exercise-induced bronchoconstriction, and lung function (FEV1) in asthmatic patients [25]. Other reviews support the findings that physical training could improve cardiorespiratory fitness and quality of life but contradict each other on pulmonary function (PEF improved but not FEV1\% and FVC) in asthmatic children [26, 27].

Considering the benefits, physical exercise is generally recommended as a supplementary therapy for asthma [2527]. However, the recommendation is conditional on controlling the intensity as a safeguard against exercise-induced bronchospasm $[5,28]$. High-intensity physical activity not only carries the risk of inducing bronchospasm but also may aggravate the side effects of sympathomimetic agents and/or corticosteroids, which are taken to reduce symptoms of airway inflammation or alleviate bronchoconstriction. Side effects include increased predisposition to stress-related 


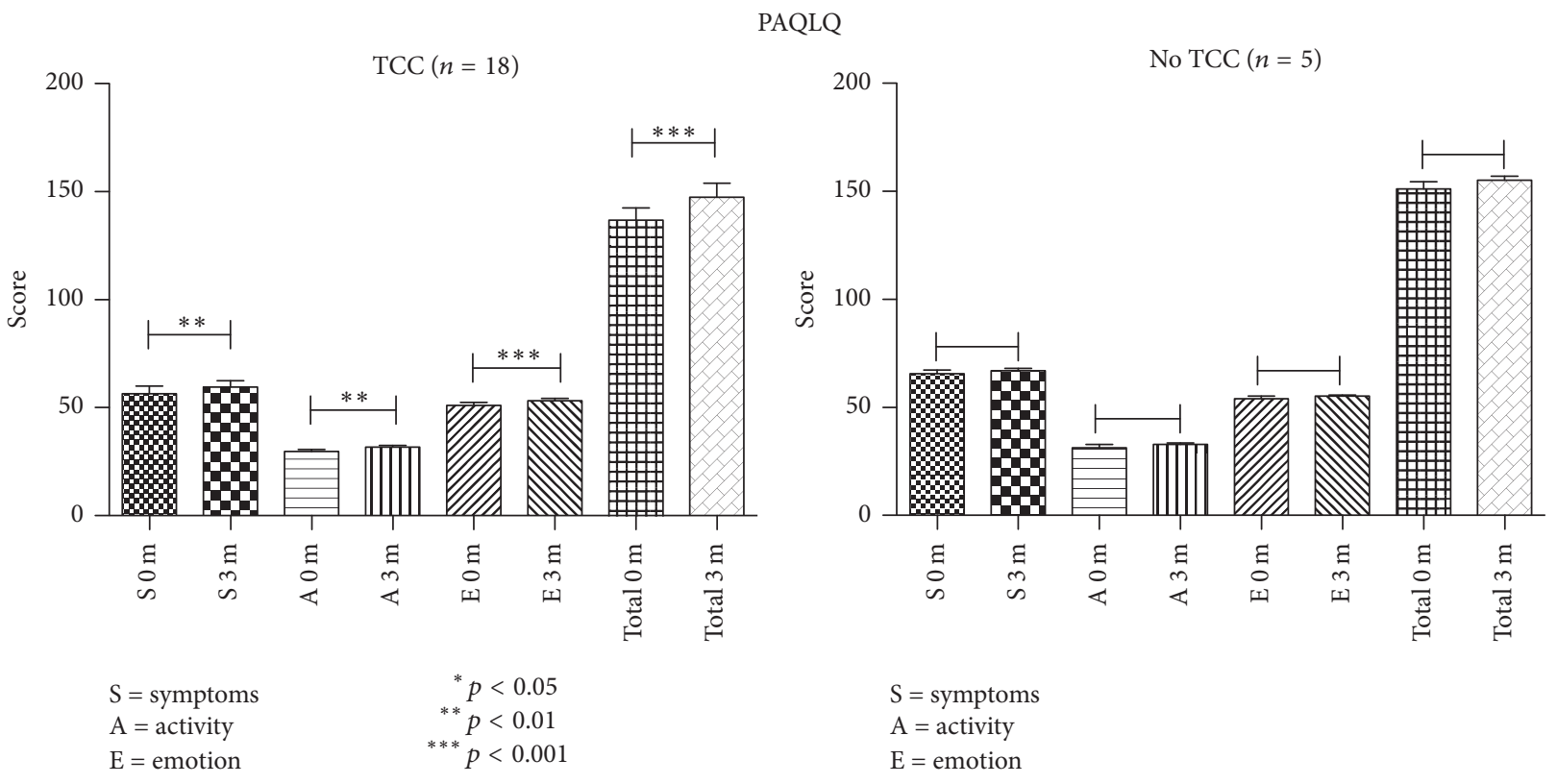

FIgURE 6: Pediatric Asthma Quality of Life Questionnaire scores in asthmatic children.

TABLE 1: Demographic and baseline values of outcome variables.

\begin{tabular}{|c|c|c|c|c|c|}
\hline & $\begin{array}{l}\text { Asthma, TCC } \\
\quad(n=20)\end{array}$ & $\begin{array}{c}\text { Asthma, no TCC } \\
(n=9)\end{array}$ & $\begin{array}{l}\text { Control, TCC } \\
\quad(n=18)\end{array}$ & $\begin{array}{l}\text { Control, no TCC } \\
(n=14)\end{array}$ & $p$ value \\
\hline Age, years $($ mean $\pm S D)$ & $10.55 \pm 0.27$ & $10.33 \pm 0.53$ & $10.11 \pm 0.21$ & $10.57 \pm 0.17$ & 0.47 \\
\hline Males, $n(\%)$ & $12(60)$ & $4(44)$ & $7(39)$ & $6(43)$ & \multirow{2}{*}{0.58} \\
\hline Females, $n(\%)$ & $8(40)$ & $5(56)$ & $11(61)$ & $8(57)$ & \\
\hline \multicolumn{6}{|c|}{ Anthropometric measurement } \\
\hline Height, cm (mean $\pm \mathrm{SD})$ & $130 \pm 4.8$ & $135 \pm 2.58$ & $142.3 \pm 8.03$ & $144.79 \pm 7.44$ & 0.68 \\
\hline Weight, kg (mean $\pm S D)$ & $36 \pm 9.27$ & $38.6 \pm 10.86$ & $35.86 \pm 6.22$ & $38.36 \pm 10.36$ & 0.95 \\
\hline $\mathrm{BMI}($ mean $\pm \mathrm{SD})$ & $17.95 \pm 3.4$ & $21.12 \pm 5.73$ & $17.64 \pm 2.49$ & $18.1 \pm 3.64$ & 0.93 \\
\hline \multicolumn{6}{|c|}{ Pulmonary function } \\
\hline FVC (\% of predicted) & $92.4 \pm 14.9$ & $96.81 \pm 20.5$ & $93.2 \pm 14.8$ & $90.6 \pm 15.2$ & 0.95 \\
\hline FEV1 (\% of predicted) & $89.2 \pm 9.1$ & $94.0 \pm 17$ & $92.7 \pm 15.0$ & $90.6 \pm 15.1$ & 0.86 \\
\hline FEV1/FVC (\%) & $91.3 \pm 7.9$ & $91.1 \pm 6.7$ & $93.3 \pm 6.4$ & $93.4 \pm 7.6$ & 0.65 \\
\hline PEFR (L/min) & $194.1 \pm 59.6$ & $186.3 \pm 35.0$ & $197.7 \pm 44.7$ & $189.1 \pm 44.3$ & 0.97 \\
\hline $\mathrm{FeNO}$ & $57.4 \pm 30.7$ & $39.2 \pm 14.9$ & $40.2 \pm 25.1$ & $26.6 \pm 17.4$ & 0.02 \\
\hline \multicolumn{6}{|c|}{ Pediatric Asthma Quality of Life Questionnaire (PAQLQ) } \\
\hline & $(n=18)$ & $(n=5)$ & & & \\
\hline Total score & $137.2 \pm 24.01$ & $151 \pm 7.61$ & & & 0.28 \\
\hline Symptom score & $56.44 \pm 15.18$ & $65.6 \pm 3.65$ & & & 0.18 \\
\hline Activity limitation score & $29.78 \pm 4.29$ & $31.4 \pm 3.36$ & & & 0.52 \\
\hline Emotional function score & $51.06 \pm 6.12$ & $54 \pm 2.92$ & & & 0.30 \\
\hline
\end{tabular}

BMI, body mass index; FEV1, forced expiratory volume in 1 second; FVC, forced vital capacity; PEFR, peak expiratory flow rate; FeNO, fractional exhaled nitric oxide. $p$ value was obtained by Kruskal-Wallis test or Mann-Whitney $U$ test or depending on the type of variables. All values are expressed as mean \pm SD.

cardiovascular complications like arrhythmia and seizures [29]. TCC, as an exercise of moderate intensity, obviates the aforementioned risks associated with high-intensity exercise.

To assess airflow obstruction, we measured FEV1/FVC ratio to assess airflow limitation, which is widely used in the diagnosis of obstructive and restrictive lung disease [30]. FEV1/FVC is strongly associated with asthma severity, even after adjusting for percentage of predicted normative value (FEV1\%) [31]. However, studies of airway inflammation by FeNO levels in asthmatic children are scarce [27]. At the 
TABLE 2: Pediatric asthma quality of life score.

\begin{tabular}{lcccc}
\hline & Subgroup & 0 wk & 12 wk & $p$ value \\
\hline \multirow{2}{*}{ Symptoms } & TCC & $56.44 \pm 15.18$ & $59.61 \pm 11.97$ & 0.0051 \\
& No TCC & $65.6 \pm 3.65$ & 0.27 \\
\hline \multirow{2}{*}{ Activity limitation } & TCC & $29.78 \pm 4.29$ & $31.72 \pm 3.44$ & $\mathbf{0 . 0 0 1 8}$ \\
& No TCC & $31.4 \pm 3.36$ & $32.8 \pm 1.48$ & 0.17 \\
\hline \multirow{2}{*}{ Emotional function } & TCC & $51.06 \pm 6.12$ & $53.17 \pm 4.42$ & 0.001 \\
& No TCC & $54 \pm 2.92$ & $55.2 \pm 1.3$ \\
\hline \multirow{2}{*}{ Total quality of life } & TCC & $137.2 \pm 24.01$ & $147.4 \pm 27.13$ & 0.5 \\
& No TCC & $151 \pm 7.61$ & $155.2 \pm 4.2$ & 0.0004 \\
\hline
\end{tabular}

TCC $(n=18)$; no TCC $(n=5)$. All values are expressed as mean \pm SD. $p$ values were obtained by comparison with the 0 wk value via Wilcoxon matched-pairs signed-rank test in the Asthma group.

TABLE 3: Results of pulmonary function and fractional exhaled nitric oxide (FeNO).

\begin{tabular}{|c|c|c|c|c|c|}
\hline Parameters & Group & Subgroup & $0 \mathrm{wk}$ & $12 \mathrm{wk}$ & $p$ value \\
\hline \multirow{4}{*}{ FEV1 (\% of predicted) } & \multirow{2}{*}{ Asthma } & TCC & $89.2 \pm 9.1$ & $94.5 \pm 14.6$ & 0.03 \\
\hline & & No TCC & $94.0 \pm 17$ & $94.6 \pm 17.4$ & 0.57 \\
\hline & \multirow{2}{*}{ Nonasthma } & TCC & $92.7 \pm 15.0$ & $95.1 \pm 17.1$ & 0.44 \\
\hline & & No TCC & $90.6 \pm 15.1$ & $89.6 \pm 16.8$ & 0.65 \\
\hline \multirow{4}{*}{ FVC (\% of predicted) } & \multirow{2}{*}{ Asthma } & TCC & $92.4 \pm 14.9$ & $94.4 \pm 18$ & 0.32 \\
\hline & & No TCC & $96.81 \pm 20.5$ & $99.4 \pm 21.3$ & 0.09 \\
\hline & \multirow{2}{*}{ Nonasthma } & TCC & $93.2 \pm 14.7$ & $93.2 \pm 14.8$ & 0.62 \\
\hline & & No TCC & $90.6 \pm 15.2$ & $88.1 \pm 17.1$ & 0.16 \\
\hline \multirow{4}{*}{ FEV1/FVC } & \multirow{2}{*}{ Asthma } & TCC & $91.3 \pm 7.9$ & $94.5 \pm 6.2$ & 0.016 \\
\hline & & No TCC & $91.1 \pm 6.7$ & $89 \pm 5.8$ & 0.07 \\
\hline & \multirow{2}{*}{ Nonasthma } & $\mathrm{TCC}^{*}$ & $93.3 \pm 6.4$ & $97.2 \pm 4.4$ & 0.026 \\
\hline & & No TCC ${ }^{*}$ & $93.4 \pm 7.6$ & $94.6 \pm 4.7$ & 0.46 \\
\hline \multirow{4}{*}{ PEFR } & \multirow{2}{*}{ Asthma } & TCC & $194.1 \pm 59.6$ & $250.2 \pm 64.7$ & $<0.0001$ \\
\hline & & No TCC ${ }^{*}$ & $186.3 \pm 35.0$ & $183.4 \pm 32.9$ & 0.55 \\
\hline & \multirow{2}{*}{ Nonasthma } & TCC & $197.7 \pm 44.7$ & $225.0 \pm 47.1$ & 0.0007 \\
\hline & & No TCC & $189.1 \pm 44.3$ & $191.8 \pm 49.2$ & 0.52 \\
\hline \multirow{4}{*}{ FeNO } & \multirow{2}{*}{ Asthma } & TCC & $57.4 \pm 30.7$ & $35.6 \pm 21.6$ & $<0.0001$ \\
\hline & & No TCC & $39.2 \pm 14.9$ & $36.1 \pm 13$ & 0.40 \\
\hline & \multirow{2}{*}{ Nonasthma } & $\mathrm{TCC}^{*}$ & $40.2 \pm 25.1$ & $30.6 \pm 21.7$ & 0.002 \\
\hline & & No TCC $^{*}$ & $26.6 \pm 17.4$ & $31 \pm 24.4$ & 0.10 \\
\hline
\end{tabular}

All values are expressed as mean \pm SD. All the comparisons were obtained by paired $t$-test with $0 \mathrm{wk}$ values or Wilcoxon matched-pairs signed-rank test depending on the distribution of the data. $p$ values were obtained from the difference among groups. ${ }^{*}$ Data are not assumed to be Gaussian distribution.

time of writing, our study is the first to demonstrate the improvement of airway inflammation by FeNO levels in asthmatic children.

FeNO is derived from the action of inducible nitric oxide synthase expressed by the airway epithelium. FeNO is increased during asthma attack and correlates with airway eosinophilia [32]. There is a large variation in FeNO levels between individuals, which may reflect the natural heterogeneity in baseline epithelial nitric oxide synthase activity and/or the contribution of other noneosinophilic factors to epithelial nitric oxide synthase activity. The upper limits of normal FeNO in Asian children depend on age, from $21 \mathrm{ppb}$ in young children to $39 \mathrm{ppb}$ in adolescents [33]. FeNO levels in healthy children depend on several non-disease-related factors, such as age, gender, height ethnicity, genetics, selfreported atopy, allergic sensitization, total IgE, time of testing, infections, a nitrate-rich diet, exercise, smoking, ambient nitric oxide, time of day and season, and environmental pollution [18, 34, 35]. Hence, we instructed participants to follow a low-nitrate diet prior to the measurement and to perform the exam in the morning at the same time prior to exercise in order to minimize possible confounding factors [32]. The effect of TCC on FeNO in children without asthma is unexpected and suggests a general effect of TCC on the FeNO level of school children. There were several studies which disclosed that FeNO level decreases during and after exercise in nonasthmatic children [36,37]. Our study is the first to reveal that FeNO level also decreases in nonasthmatic 
TABLE 4: Multiple linear regression analysis.

\begin{tabular}{lccc}
\hline $\begin{array}{l}\text { Dependent } \\
\text { variables }\end{array}$ & $\begin{array}{c}\text { Entered } \\
\text { variable(s) }\end{array}$ & Beta & $p$ value \\
\hline $\begin{array}{l}\Delta \text { FEV1 (\% of } \\
\text { predicted) }\end{array}$ & Weight & 0.53 & 0.000 \\
& Height & -0.369 & 0.010 \\
& TCC & 0.296 & 0.014 \\
\hline \multirow{2}{*}{$\Delta$ FEV1/FVC } & FEV1/FVC (\%) & -0.651 & 0.000 \\
& TCC & 0.323 & 0.001 \\
& Asthma & -0.239 & 0.013 \\
\hline PEF & TCC & 0.514 & 0.000 \\
\hline \multirow{2}{*}{$\Delta$ FeNO } & Asthma & 0.216 & 0.049 \\
\hline
\end{tabular}

All the $\Delta$ values were the difference after 3 months. Variables of age, gender, asthma, TCC, body height, body weight, baseline levels of lung function parameters, or FeNO were included in the multiple linear regression analysis.

children after 12 weeks of TCC exercise. The mechanism of decreasing FeNO level by TCC exercise is unclear and further study is needed.

A number of limitations to our study are worth noting. First, we only enrolled children with mild intermittent asthma in our study. The effect of TCC exercise on children with moderate-to-severe asthma remains unknown. Second, the sample size was relatively small due to the reluctance of school students and parents to participate to in our study. Third, our study subjects participated in the TCC class for 1 hour once a week for 3 months and were instructed to practice TCC at home by following the provided video recordings. The compliance to our scheduled exercise at home was yet to be determined. The question of the ideal intensity or frequency of TCC exercise for asthmatic children considering different severity needs to be answered. Moreover, our study was not a randomized controlled trial and biases may exist such as allocation bias because the intervention of TCC was distributed only by the wills of participants and their parents and bias in assessing outcomes because the questionnaire is relatively subjective. Those who participated in 12 -week TCC exercise may expect themselves to get better quality of life afterwards. Therefore, the results could represent regression to the mean.

Other confounding factors might also be present. We noticed higher body mass index (BMI) $(21.12 \pm 5.73)$ in asthmatic children without TCC exercise (Table 1). 44.4\% of them reached overweight status according to their age reference (normal value is 15.4-20.3 in Taiwan). It is difficult to determine whether participation in TCC exercise was influenced by being overweight, by the reluctance to exercise, or by fear of exercise-induced bronchospasm. Many studies have revealed the impact of obesity on asthma patients and recommended a weight control program for obese asthmatics [38-40]. Following exercise, BMI and lipid profiles improved in overweight children, and those with asthma have also benefited from exercise [41]. The impact of TCC exercise on obese or overweight children needs further investigation.

\section{Conclusions}

In conclusion, our study provides pilot evidence that choosing TCC as an alternative form of exercise is beneficial for asthmatic children. The results indicated that 12 weeks of TaiChi-Chuan could improve the pulmonary function, decrease airway inflammation, and improve quality of life in children with mild asthma. It also improved pulmonary function and decreased FeNO level in nonasthmatic children. Further studies are needed to evaluate the effect of TCC on children with moderate-to-severe asthma.

\section{Disclosure}

An earlier version of this work was presented as a poster at the 2013 Asia Pacific Congress of Allergy, Asthma and Clinical Immunology.

\section{Conflicts of Interest}

The authors declare that there are no conflicts of interest regarding the publication of this manuscript.

\section{Acknowledgments}

The authors are grateful to Mr. Chia-Hung Sun for his voluntary efforts in teaching TCC and Mr. Ming Wei Ong for his assistance in preparing the manuscript. The study was sponsored in part by the Institute of East West Medicine (NSC 102-2627-E-002 -006), the NTU grant: Aim For Top University Program (102R-7620), and the Research Grants from the National Taiwan University Hospital (NTUH 102002222).

\section{References}

[1] R. Beasley, U. Keil, E. Von Mutius, and N. Pearce, "Worldwide variation in prevalence of symptoms of asthma, allergic rhinoconjunctivitis, and atopic eczema: ISAAC," Lancet, vol. 351, no. 9111, pp. 1225-1232, 1998.

[2] M.-F. Liao, M.-N. Liao, S.-N. Lin, J.-Y. Chen, and J.-L. Huang, "Prevalence of allergic diseases of schoolchildren in central Taiwan: from ISAAC surveys 5 years apart," Journal of Asthma, vol. 46, no. 6, pp. 541-545, 2009.

[3] H. Milgrom and L. M. Taussig, "Keeping children with exerciseinduced asthma active," Pediatrics, vol. 104, no. 3, p. e38, 1999.

[4] M. Goodman and S. Hays, "Asthma and swimming: a metaanalysis," Journal of Asthma, vol. 45, no. 8, pp. 639-647, 2008.

[5] V. Disabella and C. Sherman, "Exercise for asthma patients: little risk, big rewards," Physician and Sportsmedicine, vol. 26, no. 6, pp. 75-84, 1998.

[6] K. V. Carson, M. G. Chandratilleke, J. Picot, M. P. Brinn, A. J. Esterman, and B. J. Smith, "Physical training for asthma," The Cochrane Database of Systematic Reviews, vol. 9, Article ID CD001116, 2013.

[7] A. J. Bidwell, B. Yazel, D. Davin, T. J. Fairchild, and J. A. Kanaley, "Yoga training improves quality of life in women with asthma," Journal of Alternative and Complementary Medicine, vol. 18, no. 8, pp. 749-755, 2012.

[8] T. Field, "Tai Chi research review," Complementary Therapies in Clinical Practice, vol. 17, no. 3, pp. 141-146, 2011. 
[9] G. Y. Yeh, M. J. Wood, B. H. Lorell et al., "Effects of Tai Chi mind-body movement therapy on functional status and exercise capacity in patients with chronic heart failure: a randomized controlled trial," American Journal of Medicine, vol. 117, no. 8, pp. 541-548, 2004.

[10] C. Lan, S.-Y. Chen, J.-S. Lai, and M.-K. Wong, "Heart rate responses and oxygen consumption during Tai CM Chuan practice," American Journal of Chinese Medicine, vol. 29, no. 3-4, pp. 403-410, 2001.

[11] J. X. Li, Y. Hong, and K. M. Chan, "Tai chi: physiological characteristics and beneficial effects on health," British Journal of Sports Medicine, vol. 35, no. 3, pp. 148-156, 2001.

[12] C. Wang, J. P. Collet, and J. Lau, "The effect of Tai Chi on health outcomes in patients with chronic conditions: a systematic review," Archives of Internal Medicine, vol. 164, no. 5, pp. 493501, 2004.

[13] S.-H. Yeh, H. Chuang, L.-W. Lin, C.-Y. Hsiao, and H. L. Eng, "Regular tai chi chuan exercise enhances functional mobility and CD4CD25 regulatory T cells," British Journal of Sports Medicine, vol. 40, no. 3, pp. 239-243, 2006.

[14] Y.-F. Chang, Y.-H. Yang, C.-C. Chen, and B.-L. Chiang, “Tai Chi Chuan training improves the pulmonary function of asthmatic children," Journal of Microbiology, Immunology and Infection, vol. 41, no. 1, pp. 88-95, 2008.

[15] M. I. Asher, U. Keil, H. R. Anderson et al., "International study of asthma and allergies in childhood (ISAAC): rationale and methods," European Respiratory Journal, vol. 8, no. 3, pp. 483491, 1995.

[16] S. Dodig, D. Richter, and R. Zrinski-Topić, "Inflammatory markers in childhood asthma," Clinical Chemistry and Laboratory Medicine, vol. 49, no. 4, pp. 587-599, 2011.

[17] H. K. Reddel, D. R. Taylor, E. D. Bateman et al., "An official American Thoracic Society/European Respiratory Society statement: asthma control and exacerbations-standardizing endpoints for clinical asthma trials and clinical practice," American Journal of Respiratory and Critical Care Medicine, vol. 180, no. 1, pp. 59-99, 2009.

[18] G. Ferrante, V. Malizia, R. Antona, G. Corsello, and S. La Grutta, "The value of FeNO measurement in childhood asthma: uncertainties and perspectives," Multidisciplinary Respiratory Medicine, vol. 8, no. 7, article 50, 2013.

[19] E. F. Juniper, G. H. Guyatt, D. H. Feeny, P. J. Ferrie, L. E. Griffith, and $\mathrm{M}$. Townsend, "Measuring quality of life in children with asthma," Quality of Life Research, vol. 5, no. 1, pp. 35-46, 1996.

[20] E. F. Juniper, G. H. Guyatt, D. H. Feeny, L. E. Griffith, and P. J. Ferrie, "Minimum skills required by children to complete health-related quality of life instruments for asthma: comparison of measurement properties," European Respiratory Journal, vol. 10, no. 10, pp. 2285-2294, 1997.

[21] C. S. K. La Scala, C. K. Naspitz, and D. Solé, "Adaptation and validation of the Pediatric Asthma Quality of Life Questionnaire (PAQLQ) in Brazilian asthmatic children and adolescents," Jornal de Pediatria, vol. 81, no. 1, pp. 54-60, 2005.

[22] H. Raat, H. J. Bueving, J. C. de Jongste, M. H. Grol, E. F. Juniper, and J. C. van der Wouden, "Responsiveness, longitudinaland cross-sectional construct validity of the Pediatric Asthma Quality of Life Questionnaire (PAQLQ) in Dutch children with asthma," Quality of Life Research, vol. 14, no. 1, pp. 265-272, 2005.

[23] O. Poachanukoon, N. Visitsunthorn, W. Leurmarnkul, and P. Vichyanond, "Pediatric asthma quality of life questionnaire
(PAQLQ): validation among asthmatic children in Thailand," Pediatric Allergy and Immunology, vol. 17, no. 3, pp. 207-212, 2006.

[24] I. Stelmach, D. Podlecka, P. Majak et al., "Validity of the pediatric asthma quality of life questionnaire in Polish children," Pediatric Allergy and Immunology, vol. 22, no. 7, pp. 660-666, 2011.

[25] P. A. Eichenberger, S. N. Diener, R. Kofmehl, and C. M. Spengler, "Effects of exercise training on airway hyperreactivity in asthma: a systematic review and meta-analysis," Sports Medicine, vol. 43, no. 11, pp. 1157-1170, 2013.

[26] A. Crosbie, "The effect of physical training in children with asthma on pulmonary function, aerobic capacity and healthrelated quality of life: a systematic review of randomized control trials," Pediatric Exercise Science, vol. 24, no. 3, pp. 472-489, 2012.

[27] V. H. M. Wanrooij, M. Willeboordse, E. Dompeling, and K. D. G. Van De Kant, "Exercise training in children with asthma: a systematic review," British Journal of Sports Medicine, vol. 48, no. 13, pp. 1024-1031, 2014.

[28] A. R. Morton and K. D. Fitch, "Australian association for exercise and sports science position statement on exercise and asthma," Journal of Science and Medicine in Sport, vol. 14, no. 4, pp. 312-316, 2011.

[29] V. Backer, A. Sverrild, and C. Porsbjerg, "Treatment of exerciseinduced bronchoconstriction," Immunology and Allergy Clinics of North America, vol. 33, no. 3, pp. 347-362, 2013.

[30] M. P. Swanney, G. Ruppel, P. L. Enright et al., "Using the lower limit of normal for the FEV1/FVC ratio reduces the misclassification of airway obstruction," Thorax, vol. 63, no. 12, pp. 1046-1051, 2008.

[31] C. D. Ramsey, J. C. Celedón, D. L. Sredl, S. T. Weiss, and M. M. Cloutier, "Predictors of disease severity in children with asthma in Hartford, Connecticut," Pediatric Pulmonology, vol. 39, no. 3, pp. 268-275, 2005.

[32] M. W. H. Pijnenburg and J. C. De Jongste, "Exhaled nitric oxide in childhood asthma: a review," Clinical and Experimental Allergy, vol. 38, no. 2, pp. 246-259, 2008.

[33] T.-C. Yao, W.-I. Lee, L.-S. Ou, L.-C. Chen, K.-W. Yeh, and J.L. Huang, "Reference values of exhaled nitric oxide in healthy Asian children aged 5 to 18 years," European Respiratory Journal, vol. 39, no. 2, pp. 378-384, 2012.

[34] T. Kovesi, R. Kulka, and R. Dales, "Exhaled nitric oxide concentration is affected by age, height, and race in healthy 9to 12-year-old children," Chest, vol. 133, no. 1, pp. 169-175, 2008.

[35] M. Antosova, A. Bencova, A. Psenkova, D. Herle, and E. Rozborilova, "Exhaled nitric oxide-circadian variations in healthy subjects," European Journal of Medical Research, vol. 14, no. 4, pp. 6-8, 2009.

[36] H. L. Petsky, J. A. Kynaston, M. McElrea, C. Turner, A. Isles, and A. B. Chang, "Cough and exhaled nitric oxide levels: what happens with exercise?" Frontiers in Pediatrics, vol. 1, article 30, 2013.

[37] B. Evjenth, T. E. Hansen, and J. Holt, "Exhaled nitric oxide decreases during exercise in non-asthmatic children," Clinical Respiratory Journal, vol. 7, no. 2, pp. 121-127, 2013.

[38] W. J. Davidson, K. A. Mackenzie-Rife, M. B. Witmans et al., "Obesity negatively impacts lung function in children and adolescents," Pediatric Pulmonology, vol. 49, no. 10, pp. 10031010, 2014. 
[39] F. B. Adeniyi and T. Young, "Weight loss interventions for chronic asthma," Cochrane Database of Systematic Reviews, vol. 7, Article ID CD009339, 2012.

[40] D. A. Beuther and E. R. Sutherland, "Overweight, obesity, and incident asthma: a meta-analysis of prospective epidemiologic studies," American Journal of Respiratory and Critical Care Medicine, vol. 175, no. 7, pp. 661-666, 2007.

[41] T. Field, "Exercise research on children and adolescents," Complementary Therapies in Clinical Practice, vol. 18, no. 1, pp. 54-59, 2012. 


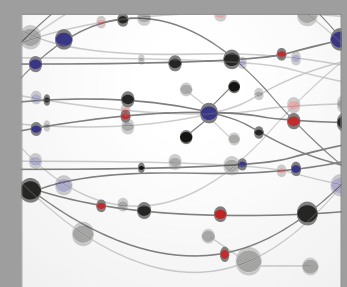

The Scientific World Journal
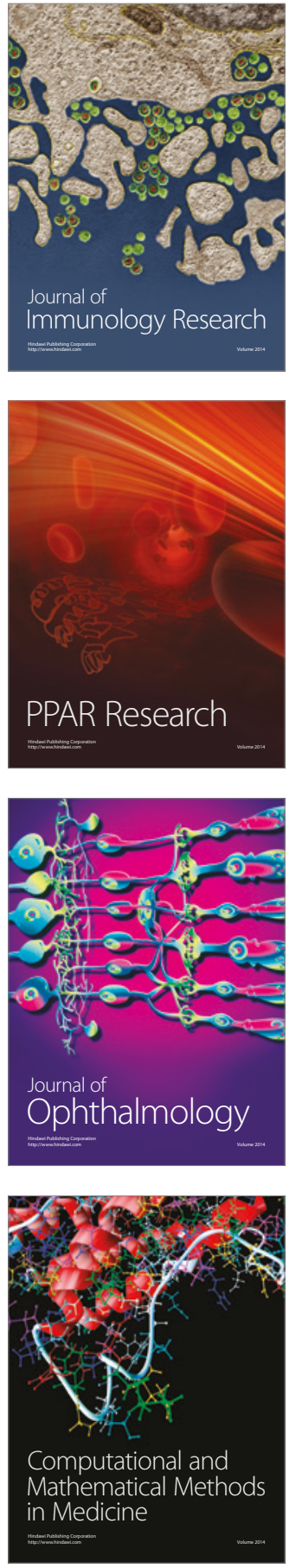

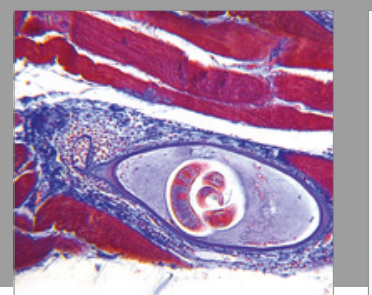

Gastroenterology Research and Practice
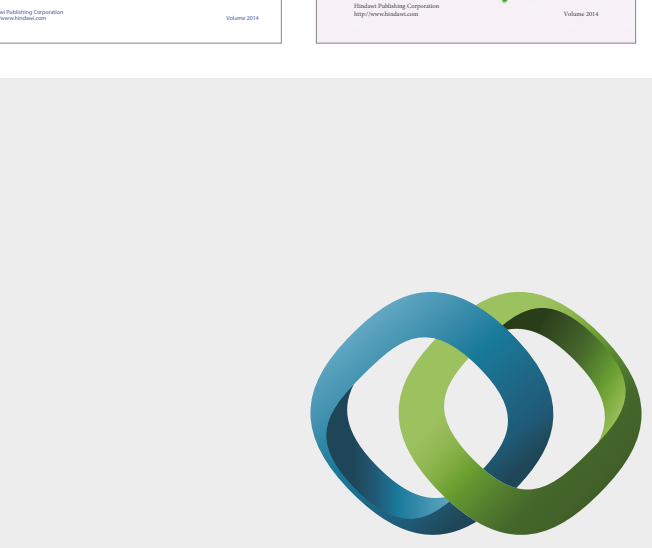

\section{Hindawi}

Submit your manuscripts at

https://www.hindawi.com
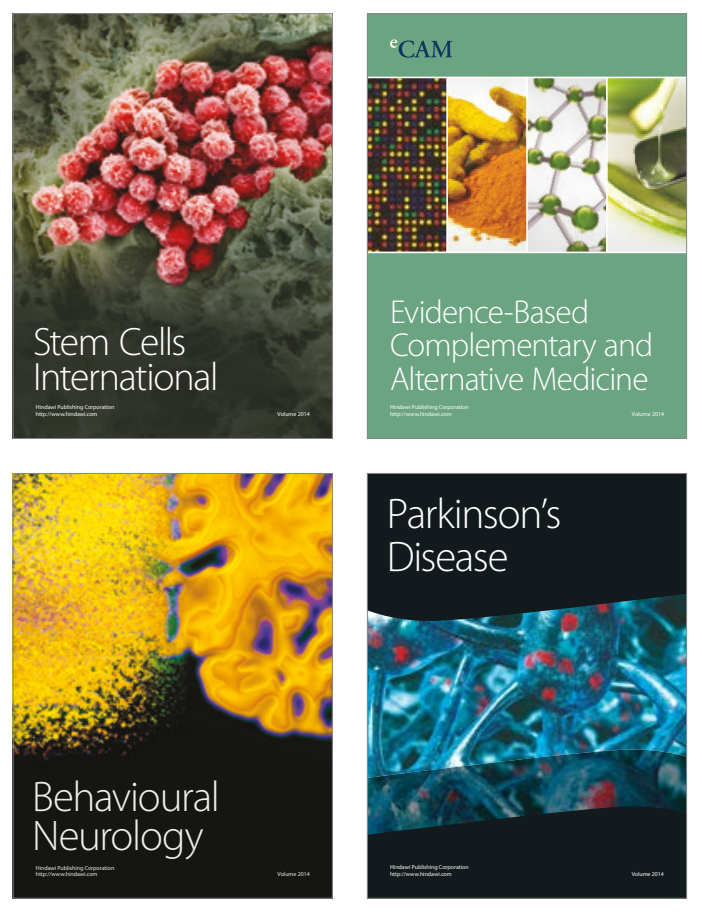
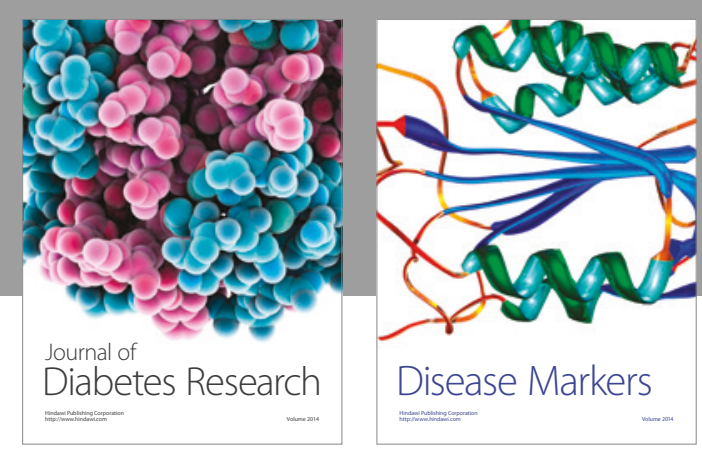

Disease Markers
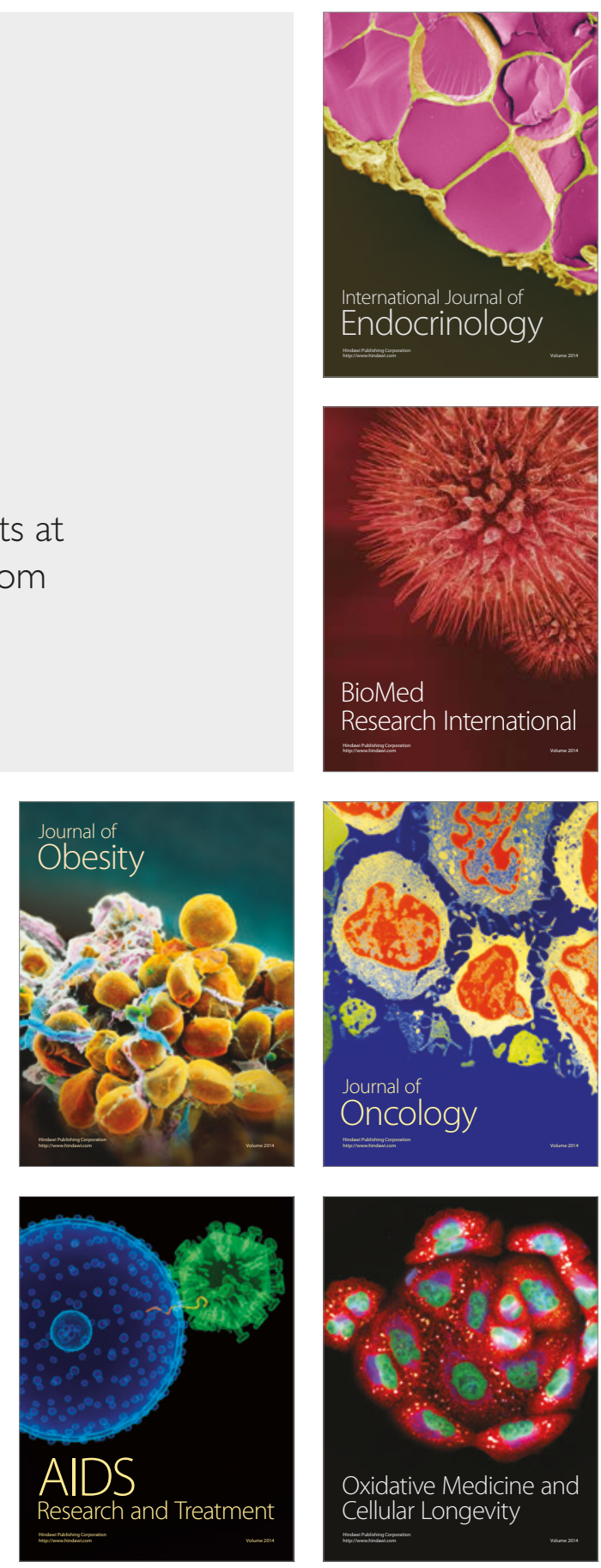